\title{
Muehrcke's lines in an adolescent boy with Kawasaki disease
}

\author{
Himanshi Chaudhary ${ }^{1} \cdot$ Vishnuvardhan Reddy Konda $^{2} \cdot$ Anju Gupta $^{1} \cdot$ Akanksha Kaushik $^{3}$ - Vinay Keshavmurthy ${ }^{3}$. \\ Surjit Singh ${ }^{4}$ (I)
}

Received: 22 June 2020 / Revised: 31 May 2021 / Accepted: 2 June 2021 / Published online: 16 June 2021

(c) International League of Associations for Rheumatology (ILAR) 2021

\section{Presentation}

A 13-year-old boy presented with intermittent, high-grade fever for 10 days that was associated with redness of eyes and oral mucosa, and generalized macular rash. Examination revealed oro-mucosal erythema, lip cracking, and extensive sheet-like periungual desquamation in all fingers and toes (Fig. 1a). No nail abnormalities were noted during the acute phase of illness. Laboratory investigations revealed leukocytosis $\left(16.8 \times 10^{9}\right.$ cells/L); thrombocytosis $\left(560 \times 10^{9}\right.$ cells $\left./ \mathrm{L}\right)$; serum albumin: $30 \mathrm{~g} / \mathrm{L}$ (normal: 35-55 g/L); ESR: $68 \mathrm{~mm} / \mathrm{h}$ (normal: 0-15 mm/h); and CRP: $56 \mathrm{mg} / \mathrm{L}$ ( $<10 \mathrm{mg} / \mathrm{L})$. Trans-thoracic two-dimensional echocardiography showed normal coronary artery dimensions. A diagnosis of Kawasaki disease (KD) was made and intravenous immunoglobulin (IVIg) $(2 \mathrm{~g} / \mathrm{kg})$ was administered over $12 \mathrm{~h}$ along with aspirin $(30 \mathrm{mg} /$ $\mathrm{kg}$ /day). He had defervesce of fever within $24 \mathrm{~h}$ of IVIg therapy following which dose of aspirin was reduced to $3 \mathrm{mg} / \mathrm{kg} / \mathrm{day}$. On 2 weeks of follow-up, he developed extensive onychomadesis (Fig. 1b) and paired, transverse, white lines in all fingernails. These lines were non-palpable and without any indentation, suggesting a diagnosis of Muehrcke's lines (Fig. 1c). At 6 weeks of follow-up, Muehrcke's lines disappeared and Beau's lines were noted in all fingernails (Fig. 1d). The follow-up echocardiogram at 6 weeks was normal.

\section{Discussion}

A myriad of nail abnormalities has been described in KD that include Beau's lines, chromonychia, pincer nail deformity, and leukonychia [1]. Muehrcke's lines are paired nonpalpable transverse white lines on nails that disappear on compression of nail beds. These are believed to occur secondary to abnormalities in nail vasculature during periods of metabolic stress [2]. These have previously been described in children with chronic malnutrition, hypoalbuminemia, liver disease, and cancer chemotherapy. KD has a component of vascular leakage during the acute phase which is associated with peripheral edema and hypoalbuminemia [3]. These lines are an important clinical finding in KD and these might reflect stress due to systemic inflammation or may be due to the hypoalbuminemia in KD.

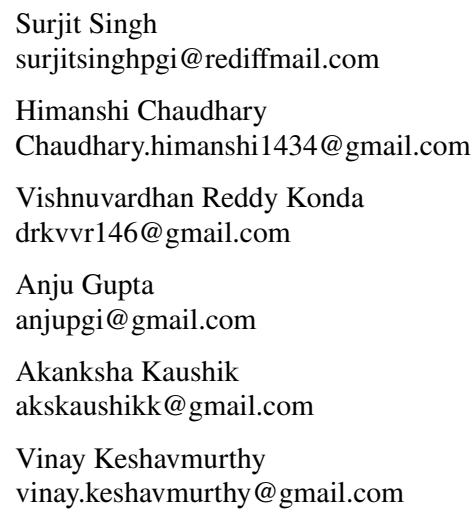

1 Allergy Immunology Unit, Advanced Pediatrics Centre, Postgraduate Institute of Medical Education and Research, Chandigarh, India 160012

2 Advanced Pediatrics Centre, Postgraduate Institute of Medical Education and Research, Chandigarh, India 160012

3 Department of Dermatology, Venereology and Leprology, Postgraduate Institute of Medical Education and Research, Chandigarh, India 160012

4 Allergy Immunology Unit, Department of Pediatrics and Chief, Advanced Pediatrics Center, Postgraduate Institute of Medical Education and Research, Chandigarh, India 160012 
Fig. 1 Cutaneous and nail changes in the adolescent boy with Kawasaki disease. a Sheetlike desquamation involving the periungual region, soles, and dorsum of both feet. $\mathbf{b}$ Blue arrows: onychomadesis (separation of the nail plate from the nail bed) seen in all fingers in convalescent-phase. c Black arrows: paired, transverse white lines suggestive of Muehrcke's lines in convalescent-phase. d Arrowheads: Beau's lines (transverse grooves on nail plate) in the same patient at 6 weeks of illness

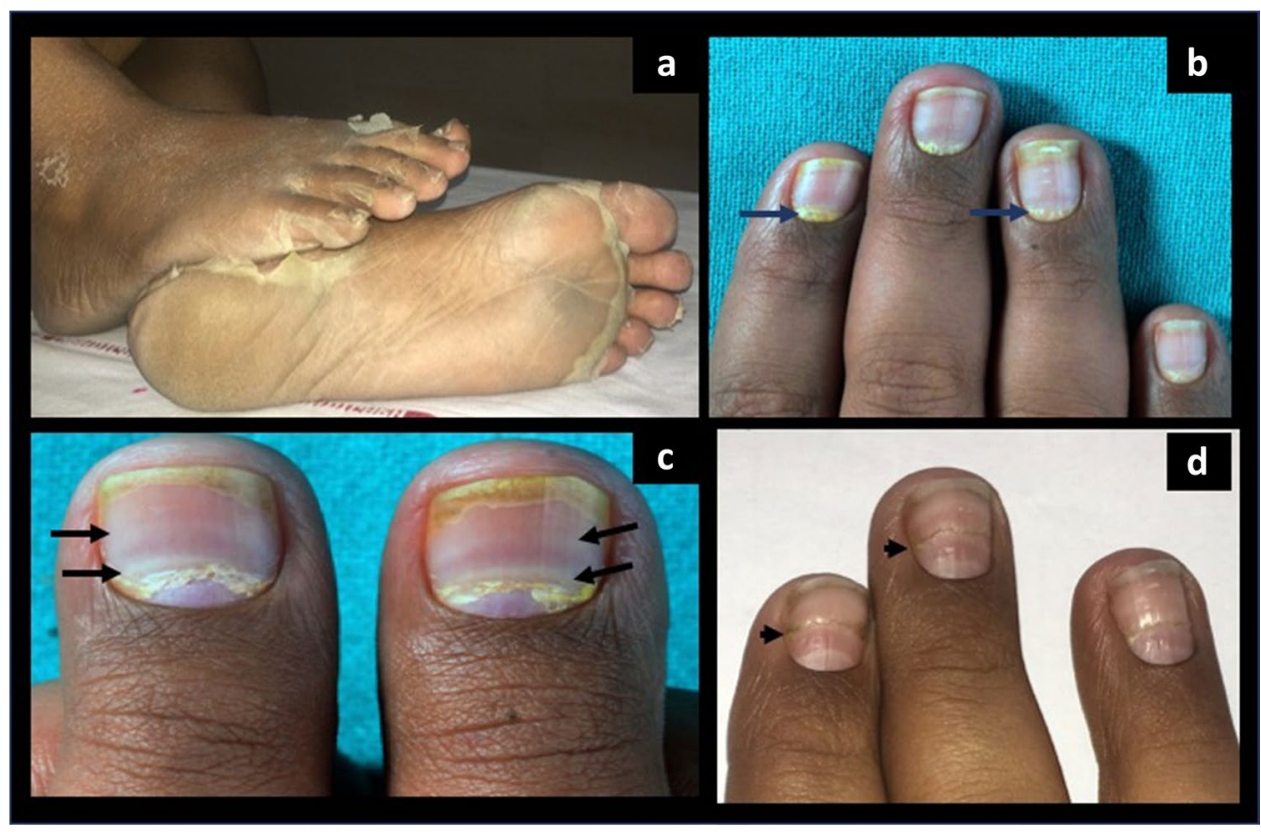

Data availability Provided.

Code availability Not applicable.

\section{Declarations}

Consent to participate Consent taken from the parent and assent from the patient.

Consent for publication Consent taken from the parent and assent from the patient.

\section{Disclosures None.}

Disclaimer No part of this manuscript has been copied or archived and published elsewhere.

\section{References}

1. Jindal AK, Bishnoi A, Dogra S, Singh S (2019) A unique combination of nail changes in a boy with Kawasaki disease. J Clin Rheumatol

2. Morrison-Bryant M, Gradon JD (2007) Muehrcke's lines. N Engl J Med 357(9):917-917

3. Terai M, Honda T, Yasukawa K, Higashi K, Hamada H, Kohno Y (2003) Prognostic impact of vascular leakage in acute Kawasaki disease. Circulation 108(3):325-330

Publisher's Note Springer Nature remains neutral with regard to jurisdictional claims in published maps and institutional affiliations. 